\title{
AN ONTOLOGY-BASED APPROACH TO STRUCTURE BUSINESS MODEL INNOVATION CASES
}

\author{
Marco Peter \\ FHNW University of Applied Sciences and Arts Northwestern Switzerland \\ Riggenbachstrasse 16, 4600 Olten, Switzerland
}

\begin{abstract}
For companies to be able to adapt to market circumstances, they need to reconfigure or even reinvent their current business model. For this, companies need support to know their possibilities for business model innovations. Using a design science approach, this research developed an ontology to systematically represent business model innovation cases. Through this ontology, reasoning on business model innovation cases can be conducted to recommend promising business models. This ontology has been successfully applied to eight cases of business model innovation.
\end{abstract}

\section{KEYWORDS}

Business Model, Business Model Innovation, Case Structure, Ontology

\section{INTRODUCTION}

Today, more and more competition takes place not only between products, services, or processes but between business models (Gassmann, Frankenberger and Csik, 2014). Therefore, companies must be able to adapt their business model since companies that have decided to undertake an innovative transformation of their business model have found themselves to be more competitive in today's market (Chesbrough, 2010; Witschel et al., 2019).

Several strategies on how to perform business model innovation (BMI) exist (Breuer, 2013; Smit et al., 2016; Geissdoerfer et al., 2017), such as the four phases method introduced by Gassmann et al. (2014) with initiation, including analysis of the ecosystem, ideation, including adaption of patterns, integration, including defining the business model in detail, and the fourth phase implementation, including the realization of the plan. But to develop software supporting the BMI process, it is crucial to have an efficient and systematic approach to collecting and representing detailed business model innovation cases. This facilitates the functionality of providing previously collected BMI cases as suggestions of new business models and thus, learn from other companies' successes or failures through the BMI cases. Nevertheless, the level of detail needs to be higher than given by the state of the art tools such as the Business Model Canvas (BMC) from Osterwalder and Pigneur (2010) or the magic triangle from Gassmann et al. (2014). The reason for this is that to compare business models only on the nine dimensions from the BMC or the four dimensions from the magic triangle would be too superficial as several BMI cases would have the same dimensions and thus, more in-depth distinctions are required. Therefore, a new structure for BMI cases is needed.

This research has the objective to answer the following research question: how does an ontology for cases of business model innovation look like? The outcome of this research will be used for a web-based tool, which should support businesses on their BMI process by facilitating the BMI process by providing previously collected real BMI cases or developed fictional BMI cases and match them to the company's business model and thus, show the impact the proposed new business model would have on the current one and provide information to estimate the transformation costs.

This paper is organized as follows: the section research method introduces the applied research method, while the section key insights describes the proposed solution for an ontology for structuring BMI-cases. The section discussion and conclusion closes this research paper with a discussion of the developed ontology based on a real-life example from the insurance sector, also, areas of further research are presented in a concluding manner. 


\section{RESEARCH METHOD}

The objective of creating an appropriate ontology for cases of business model innovation has led to the decision to apply a design-oriented research approach. I follow the Design Science Research process model proposed by Vaishnavi and Kuechler (2004), with its five research phases. In the first phase, the awareness phase, besides the literature research on BMI and ontologies, I collected two cases of BMI through semi-structured interviews with BMI experts and six cases of BMI through desk research. The cases are from companies of different sizes and different sectors to have a diversified dataset for the analysis as well as for the evaluation of the ontology. The results of this analysis in combination with the knowledge from the literature analysis were used to build the BMI case ontology. This ontology was developed using the approach from Noy and McGuinness (2001) and thus, as they suggest iterations for its development, the development and evaluation of the ontology were done iteratively to create a sophisticated outcome. The evaluation of the artefact was done by using the qualitative methods expert interviews and application of test scenarios based on the collected BMI cases to evaluate the outcome provided by the ontology. For the test scenarios, I first formulated assumptions and expectations regarding the results, which then were compared to the results within the ontology. The research results were documented and represent the groundwork for developing a recommender system of BMI cases based on individual company criteria.

\section{KEY INSIGHTS}

The concept of ontologies is promising to bring positive results regarding the capability to structure business model innovation cases systematically and to be able to perform reasoning algorithms on this structure. An ontology is a fundamental concept in knowledge representation (van Harmelen, Lifschitz and Porter, 2008) and can be defined as a "[...] formal, explicit specification of a shared conceptualization" (Studer, Benjamins and Fensel, 1998). Thus, ontologies can be used to describe a concept within a model or a program (Studer, Benjamins and Fensel, 1998). This representation enables reasoning over models of a specific concept (Bonifati et al., 2010), such as the concept of BMI.

The developed ontology for BMI cases consists of two ontologies: the business innovation case ontology and the business model ontology. The reason to develop two separate ontologies and to later merge them was because of the goal to have the ontology as reusable as possible. Thus, researchers and practitioners can reuse the combined ontology or only one ontology, depending on their needs. This results in a reduction of complexity regarding the application of the ontology.

The business innovation case ontology represents the aspects (classes) a business innovation case has according to the analyzed data from the collected BMI cases. This includes aspects such as barriers that need to be overcome to introduce the innovation, drivers and required resources for the innovation, involved parties as well as the benefits of the business innovation. In total there are 27 classes within the ontology, which are required to define a business innovation case.

The business model ontology was developed starting from the widely used tool to describe a business model in a structured way: the Business Model Canvas. This tool was developed by Osterwalder and Pigneur (2010). The tool consists of nine building blocks: customer segments, value proposition, channels, customer relationships, revenue streams, key resources, key activities, key partnerships, and cost structure (Osterwalder and Pigneur, 2010). This tool originates from four main components any business model has: offering, customer interface, infrastructure, and financial aspects. The component offering focuses on the products and services a company offers to its customers and can be seen as a value proposition delivered to the customer (Osterwalder, 2004; Zarei et al., 2011). Customer interface represents the value delivery and includes the channels used to interact with a customer and thus, the go-to-market strategy, as well as the customer segments and the relationships towards the company's customers (Osterwalder, 2004; Zarei et al., 2011). The infrastructure component is essential to determine the needs to deliver the offering according to the customer interface and represents the value creation of a business (Osterwalder, 2004; Zarei et al., 2011). Financial aspects involve the cost structure as well as the revenue model of a company and thus, reflect the value capturing attempts of a business. This knowledge of business models was altogether included in the business model ontology and expanded by different methods from the literature. One of these methods was the innovation ecosystem approach for creating new innovations and new business models. Innovation ecosystems 
can be represented in quadruple helixes including individuals, the government, academic institutes, and businesses (Rabelo and Bernus, 2015; Schütz et al., 2018). In total there are 97 classes within the ontology, which are required to define a business model in detail.

Figure 1 illustrates an excerpt of the developed ontology to structure BMI cases systematically. The excerpt only shows the modeled part for the infrastructure of the BMI case ontology since the entire ontology would be too big to be illustrated on a single page.

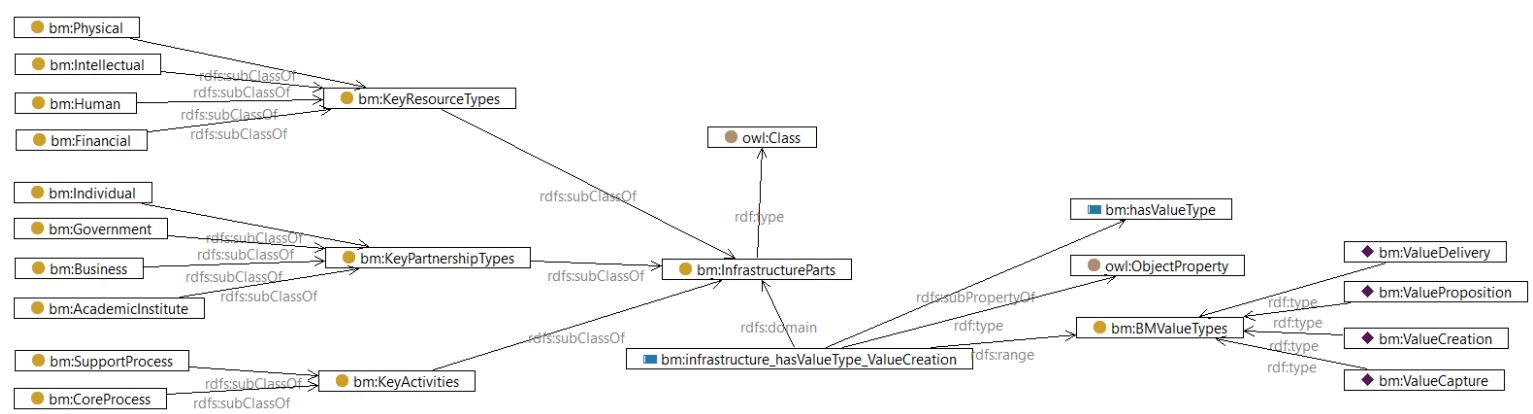

Figure 1. Excerpt of the business model infrastructure parts from the BMI case ontology

\section{DISCUSSION AND CONCLUSION}

As part of the evaluation of the BMI case ontology, the eight previously collected BMI cases were applied to the ontology to assess its applicability for cases of different sectors and company sizes. An excerpt from one of these cases, an insurance company related case, is shown in Figure 2, where the infrastructure aspect of the case is shown within the ontology.

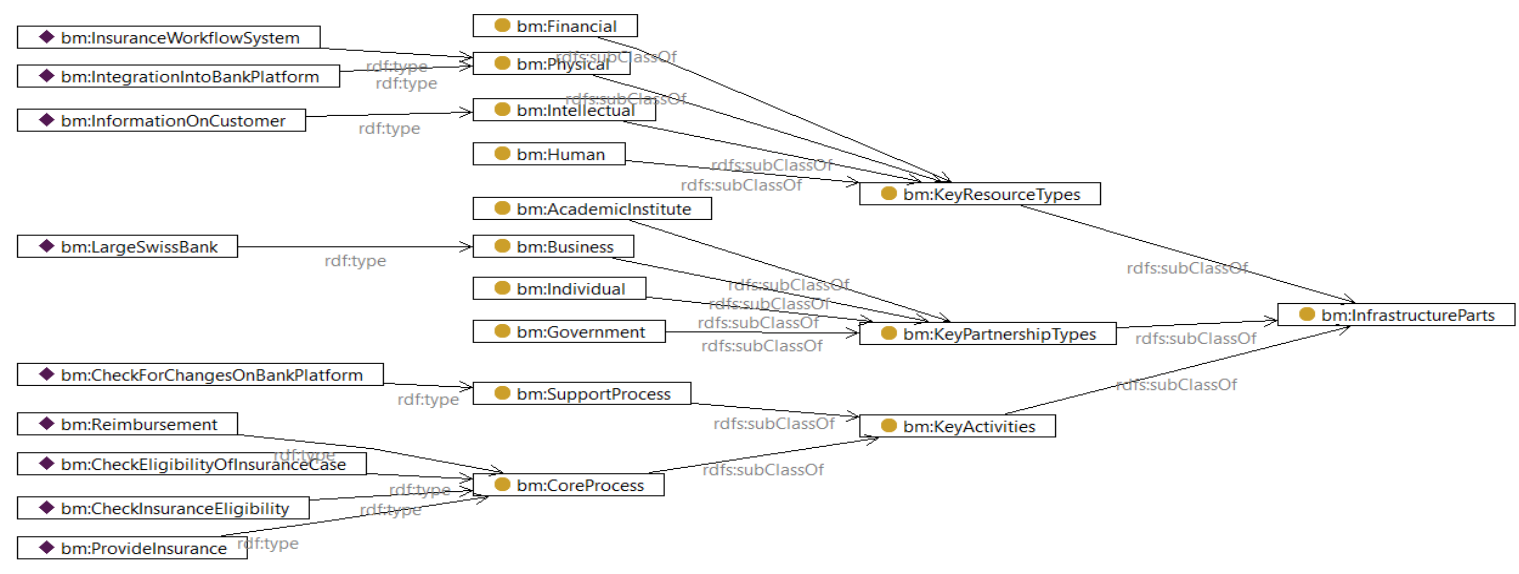

Figure 2. Excerpt of the business model infrastructure parts from the BMI case ontology for the insurance case example

The evaluation showed that the ontology is capable to handle BMI cases of different sectors and company sizes. Nevertheless, to provide more details of a BMI case, it would be useful to provide industry-specific information within the ontology as well. For example, within the construction sector, the aspect of the partnership is essential, while for the hotel industry the customer relationship is key. Thus, it would be helpful to have an even higher level of detail for specific aspects of the BMI case ontology depending on the related sector of the BMI case.

There are other business model innovation tools such as the 55 business model cards from Gassmann (2014) or the business model pattern tool by Remane et al. (2017). These tools are helpful for a business, especially the 55 business model cards as they provide suggestions for business models during the ideation phase of the BMI process. Yet, it would be helpful to have a recommendation for a new business model based on a current 
business model to estimate the consequences of implementing the proposed business model. Thus, this BMI case ontology is the first step towards the development of a business model recommender system to facilitate the innovation process of businesses. Nevertheless, the two tools by Gassmann (2014) and Remane et al. (2017) can be integrated into the ontology and act as partial business model innovation cases and therefore, enrich the case database of the BMI case ontology.

This paper aims to contribute an ontology for systematically structuring BMI cases. Therefore, this paper has discussed an ontology for potential cases of BMI and showed that it is not only technically possible, but it also advances the current state of the art. Thus, the research question of how an ontology for cases of business model innovation could look like has been answered. Further research is now required regarding the integration of the ontology into a recommender system (Bonifati et al., 2010; Witschel et al., 2015) and adapting the ontology to different sectors. Thus, further research on this topic is necessary and promising and might lead to relevant academic and practical insights.

\section{REFERENCES}

Bonifati, A. et al. (2010) 'Ontological Matchmaking in Recommender Systems', pp. 1-28. Available at: http://arxiv.org/abs/1010.2148.

Breuer, H. (2013) 'Lean Venturing: Learning to Create new Business Through Exploration, Elaboration, Evaluation, Experimentation, and Evolution', International Journal of Innovation Management, 17(3), pp. 1-22. doi: 10.1142/S1363919613400136.

Chesbrough, H. (2010) 'Business model innovation: Opportunities and barriers', Long Range Planning, 43(2-3), pp. 354-363. doi: 10.1016/j.lrp.2009.07.010.

Gassmann, O., Frankenberger, K. and Csik, M. (2014) The business model navigator: 55 models that will revolutionise your business. Harlow, England: Pearson Education Limited.

Geissdoerfer, M., Savaget, P. and Evans, S. (2017) 'The Cambridge Business Model Innovation Process', Procedia Manufacturing, 8(October 2016), pp. 262-269. doi: 10.1016/j.promfg.2017.02.033.

Noy, N. F. and McGuinness, D. L. (2001) ‘Ontology Development 101: A Guide to Creating Your First Ontology’, Stanford Knowledge Systems Laboratory, p. 25. doi: 10.1016/j.artmed.2004.01.014.

Osterwalder, A. (2004) The business model ontology - a proposition in a design science approach, Ph.D. dissertation. University of Lausanne.

Osterwalder, A. and Pigneur, Y. (2010) Business Model Generation. Hoboken, New Jersey: John Wiley \& Sons Inc.

Rabelo, R. J. and Bernus, P. (2015) 'A holistic model of building innovation ecosystems', IFAC-PapersOnLine, 28(3), pp. 2250-2257. doi: 10.1016/j.ifacol.2015.06.423.

Remane, G. et al. (2017) 'The Business Model Pattern Database-A Tool For Systematic Business Model Innovation', International Journal of Innovation Management, 21(1). doi: 10.1142/S1363919617500049.

Schütz, F. et al. (2018) 'Defining functional roles for research institutions in helix innovation networks', Journal of Technology Management \& Innovation, 13(4), pp. 47-54.

Smit, S. et al. (2016) 'Business Model Boutique: A Prêt-à-Porter Solution for Business Model Innovation in SMEs', in IFIP International Federation for Information Processing, pp. 579-587. doi: 10.1007/978-3-319-45390-3_49.

Studer, R., Benjamins, V. R. and Fensel, D. (1998) 'Knowledge Engineering: Principles and methods', Data \& Knowledge Engineering, 25, pp. 161-197. doi: https://doi.org/10.1016/S0169-023X(97)00056-6.

Vaishnavi, V. and Kuechler, B. (2004) 'Design Science Research in Information Systems Overview of Design Science Research', Ais, p. 45. doi: 10.1007/978-1-4419-5653-8.

van Harmelen, F., Lifschitz, V. and Porter, B. (2008) Handbook of Knowledge Representation. 3rd edn. Elsevier Science.

Witschel, H. F. et al. (2015) 'A new Retrieval Function for Ontology-Based Complex Case Descriptions', International Workshop Case-Based Reasoning CBR-MD 2015.

Witschel, H. F. et al. (2019) 'Case Model for the RoboInnoCase Recommender System for Cases of Digital Business Transformation: Structuring Information for a Case of Digital Change', in IC3K 2019 - Proceedings of the 11th International Joint Conference on Knowledge Discovery, Knowledge Engineering and Knowledge Management, pp. 62-73. doi: 10.5220/0008064900620073.

Zarei, B., Nasseri, H. and Tajeddin, M. (2011) 'Best practice network business model for internationalization of small and medium enterprises', Journal of International Entrepreneurship, 9(4), pp. 299-315. doi: 10.1007/s10843-011-0080-3. 